\title{
Abundance and characteristics of microplastics in commercial marine fish from Malaysia
}

\begin{abstract}
Plastic debris is widespread and ubiquitous in the marine environment and ingestion of plastic debris by marine organisms is well-documented. Viscera and gills of 110 individual marine fish from 11 commercial fish species collected from the marine fish market were examined for presence of plastic debris. Isolated particles were characterized by Raman spectroscopy, and elemental analysis was assessed using energy-dispersive X-ray spectroscopy (EDX). Nine (of 11) species contained plastic debris. Out of 56 isolated particles, $76.8 \%$ were plastic polymers, $5.4 \%$ were pigments, and $17.8 \%$ were unidentified. Extracted plastic particle sizes ranged from 200 to $34,900 \mu \mathrm{m}$ (mean $=2600 \mu \mathrm{m} \pm 7.0 \mathrm{SD}$ ). Hazardous material was undetected using inorganic elemental analysis of extracted plastic debris and pigment particles. The highest number of ingested microplastics was measured in Eleutheronema tridactylum and Clarias gariepinus, suggesting their potential as indicator species to monitor and study trends of ingested marine litter.
\end{abstract}

Keyword: Microplastics; Commercial fish; Ingestion; Raman spectroscopy 